\title{
Treatment of Cavernous Sinus Hemangiomas with Gamma Knife Radiosurgery as a Primary and Sole Therapy
}

\author{
Ozgur KARDES, Kadir TUFAN \\ Baskent University, School of Medicine, Department of Neurosurgery, Ankara, Turkey \\ Corresponding author: Ozgur KARDES okardes@gmail.com
}

\section{ABSTRACT}

AIM: To evaluate the effectiveness of Gamma Knife radiosurgery (GKRS) as the primary and only therapy for the treatment of cavernous sinus hemangiomas $(\mathrm{CSH})$ and to report the tumor volume dynamics, course of symptoms, and complications after stereotactic radiosurgery.

MATERIAL and METHODS: A total of $10 \mathrm{CSH}$ patients were treated with GKRS using a median margin dose of $14.2 \mathrm{~Gy}$ (range 13-16Gy). The median follow-up period was 42 months (range 12-85 months). Tumor volumes were calculated from magnetic resonance images before treatment and compared with those after treatment.

RESULTS: Prior to the treatment, all patients complained of headache and retro-orbital pain, and six patients complained of diplopia due to abducens nerve paralysis. Within six months of treatment, all patients declared some improvement in headache and retro-orbital pain, and abducens nerve paralysis recovered fully in all six patients. At the first-year follow-up, at least $74 \%$ decrease in tumor volume was noted with average tumor volume reduction of $90.2 \%$ in all treated patients. Tumors less than $6 \mathrm{~cm}^{3}$ in volume nearly disappeared at 24 months. No tumor progression, re-growth, or radiation-induced adverse effects were noted in our patients.

CONCLUSION: Characteristic radiological features that enable identification of CSH avert the need for an open biopsy for diagnosis. Under suitable circumstances, GKRS may be considered as the primary and only therapy for CSH. GKRS has favorable outcomes in the treatment of $\mathrm{CSH}$, demonstrating good tumor shrinkage, symptom recovery, and low incidence of side effects.

KEYWORDS: Stereotactic radiosurgery, Gamma Knife, Cavernous sinus hemangiomas

\section{INTRODUCTION}

$\longrightarrow$ avernous sinus hemangiomas (CSH) are rare, benign, and intracranial vascular neoplasms that account for approximately $3 \%$ of all cavernous sinus tumors (9). $\mathrm{CSH}$ differ from cavernous hemangiomas (cavernomas) as they are extra-axial, vascular, and produce symptoms due to tumor progression and mass effect $(9,10)$. These lesions predominantly occur in middle-aged women and may cause neurological symptoms such as headaches, retro-orbital pain, and progressive ocular movement disorders $(10,11)$.

Complete microsurgical removal of $\mathrm{CSH}$ is curative, but is associated with some well-known risks. Due to the hypervascular nature and location of these tumors, microsurgery may be complicated by severe intra-operative hemorrhage and post-operative cranial nerve deficits $(9,11,12,14,16,24)$.

Over the last two decades, some promising results have been reported in the treatment of $\mathrm{CSH}$. Very low morbidity and almost no mortality were reported when stereotactic radiosurgery (SRS) was used to treat $\mathrm{CSH}$. While previous $\mathrm{CSH}$ treatment studies reported the status of post-operative residual tumors, today most centers using SRS as the primary and often the sole treatment modality report favorable outcomes (1-3,5-7,13,15,17,21,22).

The aim of the current study is to evaluate the use of Gamma Knife radiosurgery (GKRS) as the primary treatment modality for $\mathrm{CSH}$ based on pre- and post-operative clinical and radiological findings. 


\section{MATERIAL and METHODS}

Between 2010 and 2018, a total of $10 \mathrm{CSH}$ patients were treated with GKRS at Baskent University Adana Dr. Turgut Noyan Medical Center Gamma Knife Unit. Data on the demographic, clinical, radiological, and radiosurgical characteristics of the patients and their tumors were obtained from patients' charts retrospectively. Tumor volumes were evaluated using magnetic resonance (MR) images before and after the treatment using follow-up images acquired 2, 6 and 12 months post-treatment, and yearly thereafter.

Tumors that demonstrated low- or iso-intensity on T1weighted sequences, well-defined marked hyper-intensity on T2-weighted sequences, and fluid-attenuated inversion recovery (FLAIR) images were identified as CSH. In contrast, meningiomas and schwannomas show low- or iso-intensity on T2-weighted sequences and FLAIR images. After contrast agent administration, CSH demonstrate significant and homogenous enhancement on the T1-weighted post-contrast images. In addition, CSH typically lack a dural tail (Figure 1A$\mathrm{C})$. Due to these unique identifying features, brain magnetic resonance imaging was the primary tool used for $\mathrm{CSH}$ diagnosis in our patients. There was no history of microsurgical treatment or open biopsy in our patients.

\section{Radiosurgical Technique}

Leksell G stereotactic frame (Elekta, Sweden) was applied to the patient's head under local anesthesia and brain MR images were obtained. The Leksell Gamma Plan 10.1 software was used for dose planning. The aim of dose planning was to cover the whole lesion with multi-isocenters while adjusting the radiation dose for critical structures such as the optic apparatus (below 8 Gy) and the brainstem (below 12 Gy). Leksell Gamma Knife 4-C was used for the treatment.

\section{Volumetric Evaluation Technique}

Prior to the treatment, tumor volumes were measured and noted using the Leksell Gamma Plan 10.1 software. Tumor volumes after the treatment were calculated as the sum of the areas contoured on each slice multiplied by slice thickness. Previous volumetric studies using the trapezoidal rule formula demonstrate that with accurate delineation on at least five slices, the calculated volume would have an expected error rate of $10 \%$ or less (18).

All volumetric measurements were made on enhanced T1weighted MR images.

The volume response was classified according to the Wang grading system as follows (22):

Grade 1- Good response: Shrinkage of more than $50 \%$ of the tumor volume.

Grade 2- Partial response: Shrinkage of more than 25\% and less than $50 \%$ of tumor volume.

Grade 3- No change: Less than $25 \%$ shrinkage of the tumor volume.

\section{RESULTS}

The study included five females and five males with a median age of 49 years (range 15-68 years). CSH was located on the right side in three patients and to the left in seven patients. Prior to treatment, all patients complained of headache and retro-orbital pain. In addition, six patients complained of diplopia and abducens nerve paralysis during the initial neurological examination (Table I). The median tumor volume was $4.98 \mathrm{~cm}^{3}$ (range 2-10.9 $\mathrm{cm}^{3}$ ) and median margin dose was 14.2 Gy (range 13-16 Gy).

\section{Clinical Outcome}

The median follow-up period of $10 \mathrm{CSH}$ patients treated with GKRS was 42 months (range12-85 months). Following treatment, all patients declared some improvement in their previous headache and retro-orbital pain, while six patients reported complete resolution of headache. Within six months of treatment, abducens nerve paralysis and accompanying diplopia recovered fully in all six patients. No adverse events related to radiosurgical treatment were recorded.

\section{Tumor Response}

After GKRS treatment, marked tumor regression was observed within the first 6 months of treatment. At the first-year followup, treated tumors decreased in volume by at least $74 \%$. Furthermore, volume reduction continued at the 24- and 36month evaluations. Tumors less than $6 \mathrm{~cm}^{3}$ in volume nearly disappeared at 24 months. After a median follow-up period of 42 months, tumor volumes reduced more than $90.2 \%$ on average (Table II). There was no tumor progression or regrowth in our patients (Figures 2, 3).

\section{DISCUSSION}

Microsurgical removal of $\mathrm{CSH}$ is challenging because of well-known risks associated with cavernous sinus surgery including severe operative bleeding and cranial nerve deficits. Moreover, it was recently reported that total microsurgical removal could only be managed in $44 \%-55 \%$ of patients (8).

Previously, treating inoperable and residual $\mathrm{CSH}$ patients with conventional radiotherapy achieved satisfactory tumor shrinkage. Subsequently, SRS was used as a more conformal treatment modality given its ability to preserve critical structures such as the optic apparatus, brain stem, and pituitary gland. In 1994, Iwai et al. reported the first successful treatment of a residual CSH with Gamma Knife (4). However, most early reports about CSH treatment with SRS were for residual tumors with a small sample size.

In 2012, Wang et al. presented a systematic review and metaanalysis on radiosurgical treatment of $\mathrm{CSH}$ that included 59 patients. After a mean follow-up of 49.2 months, they reported remarkable shrinkage in $67.8 \%$ of patients, partial response in $25.4 \%$, and no change in $6.8 \%$ of the patients. Additionally, they reported only one case of trigeminal nerve disturbance as a side effect (24).

In 2015, Tang et al. published their case series that included $53 \mathrm{CSH}$ patients treated with the Gamma Knife. They reported 
$100 \%$ tumor control rate with over $80 \%$ reduction in tumor volume in $55 \%$ of patients after a 24 -month radiological follow-up period. Thirty three of the 53 patients demonstrated significant improvements in their clinical status, although two patients showed temporary clinical deterioration (20). Recently, Lee et al. reported a multi-center retrospective study that included $31 \mathrm{CSH}$ cases. Twenty of these patients underwent Gamma Knife as the primary treatment. They demonstrated more than $50 \%$ reduction in tumor volume within 6 months in all patients. Also, no delayed tumor regrowth, new cranial neuropathy or radiation-induced adverse effects were observed (7).

$\mathrm{CSH}$ show low- or iso-intensity on T1-weighted images and well-defined marked hyper-intensity (as bright as the cerebrospinal fluid signal) on T2-weighted and FLAIR images. Furthermore, they show strong homogenous enhancement on T1-weighted images after injection of the contrast agent gadolinium. Typically, CSH lack a dural tail. Therefore, it is possible to differentiate CSH from pituitary adenomas, meningiomas, and schwannomas based on these unique radiological features (Figure $1 \mathrm{~A}-\mathrm{C}$ ). Such characteristic radiological findings avert the need for an open biopsy for exact diagnosis of CSH (1). This is an advantage because, similar to microsurgical removal, open biopsy may also result in significant morbidity $(5,10,19,23)$.

Since CSH has satisfactorily unique radiological features that aid its diagnosis, treating these tumors with radiosurgery as the primary and only therapy seems rational. The aim of the current study was to evaluate the effectiveness of GKRS as the primary and only therapy for the treatment of $\mathrm{CSH}$ and to report the tumor volume dynamics, course of symptoms, and complications after treatment.

Table I: Characteristics of the Patients Enrolled in the Study

\begin{tabular}{ccccccc}
\hline $\begin{array}{c}\text { Case } \\
\text { No. }\end{array}$ & $\begin{array}{c}\text { Age (yrs) } \\
\text { /sex }\end{array}$ & $\begin{array}{c}\text { Tumor Position } \\
\text { (site) }\end{array}$ & $\begin{array}{c}\text { Clinical } \\
\text { Presentation }\end{array}$ & Symptoms & $\begin{array}{c}\text { Length of follow-up } \\
\text { (month) }\end{array}$ & $\begin{array}{c}\text { Post-GKS Symptom } \\
\text { Change }\end{array}$ \\
\hline 1 & $35 / \mathrm{F}$ & left & headache + diplopia & VI. nerve palsy & 85 & disappeared \\
\hline 2 & $15 / \mathrm{M}$ & left & headache + diplopia & VI. nerve palsy & 66 & disappeared \\
\hline 3 & $29 / \mathrm{F}$ & right & headache + diplopia & VI. nerve palsy & 61 & disappeared \\
\hline 4 & $53 / \mathrm{F}$ & left & headache + diplopia & VI. nerve palsy & 51 & disappeared \\
\hline 5 & $43 / \mathrm{M}$ & left & headache + diplopia & VI. nerve palsy & 44 & disappeared \\
\hline 6 & $58 / \mathrm{M}$ & left & headache & None & 34 & disappeared \\
\hline 7 & $55 / \mathrm{M}$ & left & headache + diplopia & VI. nerve palsy & 24 & disappeared \\
\hline 8 & $68 / \mathrm{F}$ & right & headache & None & 22 & disappeared \\
\hline 9 & $68 / \mathrm{M}$ & right & headache & None & 19 & disappeared \\
\hline 10 & $67 / F$ & left & headache & None & 12 & disappeared \\
\hline
\end{tabular}

Table II: Tumor Volume Response After the First Year

\begin{tabular}{cccccc}
\hline Case no & $\begin{array}{c}\text { Pre-GKS Volume } \\
\left(\mathbf{c m}^{\mathbf{3}}\right)\end{array}$ & $\begin{array}{c}\text { Peripheral Dose } \\
(\mathbf{5 0} \text { isodose) }(\mathbf{G y})\end{array}$ & $\begin{array}{c}\text { Post-GKS } \\
\text { Volume }\left(\mathbf{c m}^{\mathbf{3}}\right)\end{array}$ & $\begin{array}{c}\text { Volume Reduction } \\
(\mathbf{\%})\end{array}$ & $\begin{array}{c}\text { Volume response } \\
\text { grade }\end{array}$ \\
\hline 1 & 3.76 & 14 & 0.2 & 94 & $\mathrm{I}$ \\
\hline 2 & 3.25 & 14 & 0.1 & 97 & $\mathrm{I}$ \\
\hline 3 & 1.99 & 15 & 0.21 & 89 & $\mathrm{I}$ \\
\hline 4 & 8.33 & 13 & 1.0 & 87 & $\mathrm{I}$ \\
\hline 5 & 5.40 & 13 & 0.2 & 96 & $\mathrm{I}$ \\
\hline 6 & 4.48 & 15 & 0.3 & 95 & $\mathrm{I}$ \\
\hline 7 & 2.67 & 16 & 0.3 & 88 & $\mathrm{I}$ \\
\hline 8 & 10.97 & 13 & 1.26 & 88 & $\mathrm{I}$ \\
\hline 9 & 3.87 & 16 & 1.0 & 74 & $\mathrm{I}$ \\
\hline 10 & 5.14 & 13 & 0.3 & 94 & \\
\hline
\end{tabular}



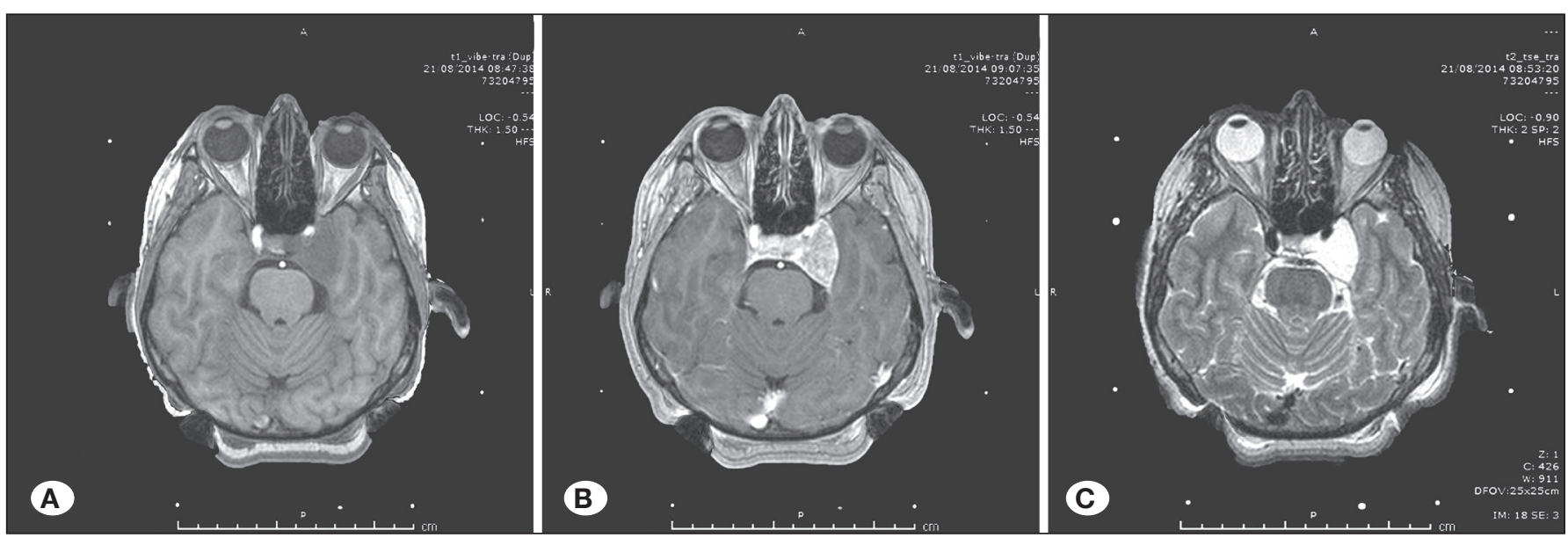

Figure 1: Prior to treatment,T1-weighted pre-contrast (A), post-contrast (B), and T2-weighted (C) magnetic resonance images demonstrate an expanding lesion in the left cavernous sinus. The lesion has no dural tail on T1-weighted post-contrast images and shows well-defined marked hyper-intensity on T2-weighted images that are unique radiological features in cavernous sinus hemangioma diagnosis.

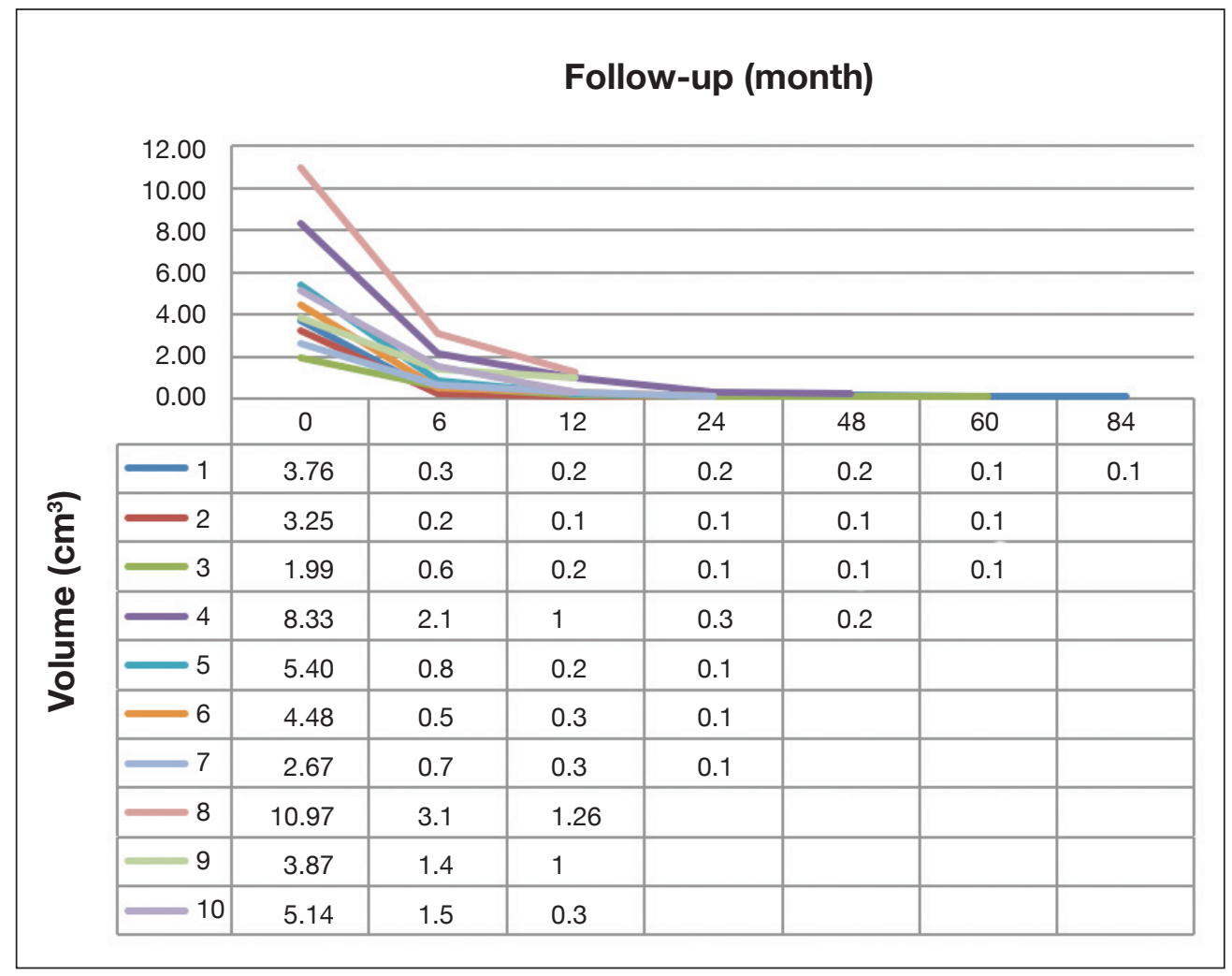

Figure 2: Tumor volume response according to follow-up periods.

In our case series, GKRS resulted in a tumor volume response of grade 1 on the Wang grading system after a median follow-up period of 42 months. Our study suggests that the beneficial effects of GKRS may mainly occur within the first 6 months of treatment. Indeed, tumor shrinkage began as early as 2 months after treatment, and at least $74 \%$ of tumor volume reduction was achieved during the first year. Average tumor reduction at first-year follow-up was $90.2 \%$. After the first year, the tumor shrinkage continued at a slower pace.
Moreover, abducens nerve paralysis recovered in all patients, and severity of headache and retro-orbital pain was reduced or eliminated within the first six months. No radiation-induced neuropathies or other side effects were observed.

Our findings are in agreement with other recently published studies in the literature. Small sample size, stemming from the rarity of this disease, is the most important limitation of our retrospective study. Prospective, multi-center studies with large sample sizes are needed in the future. 

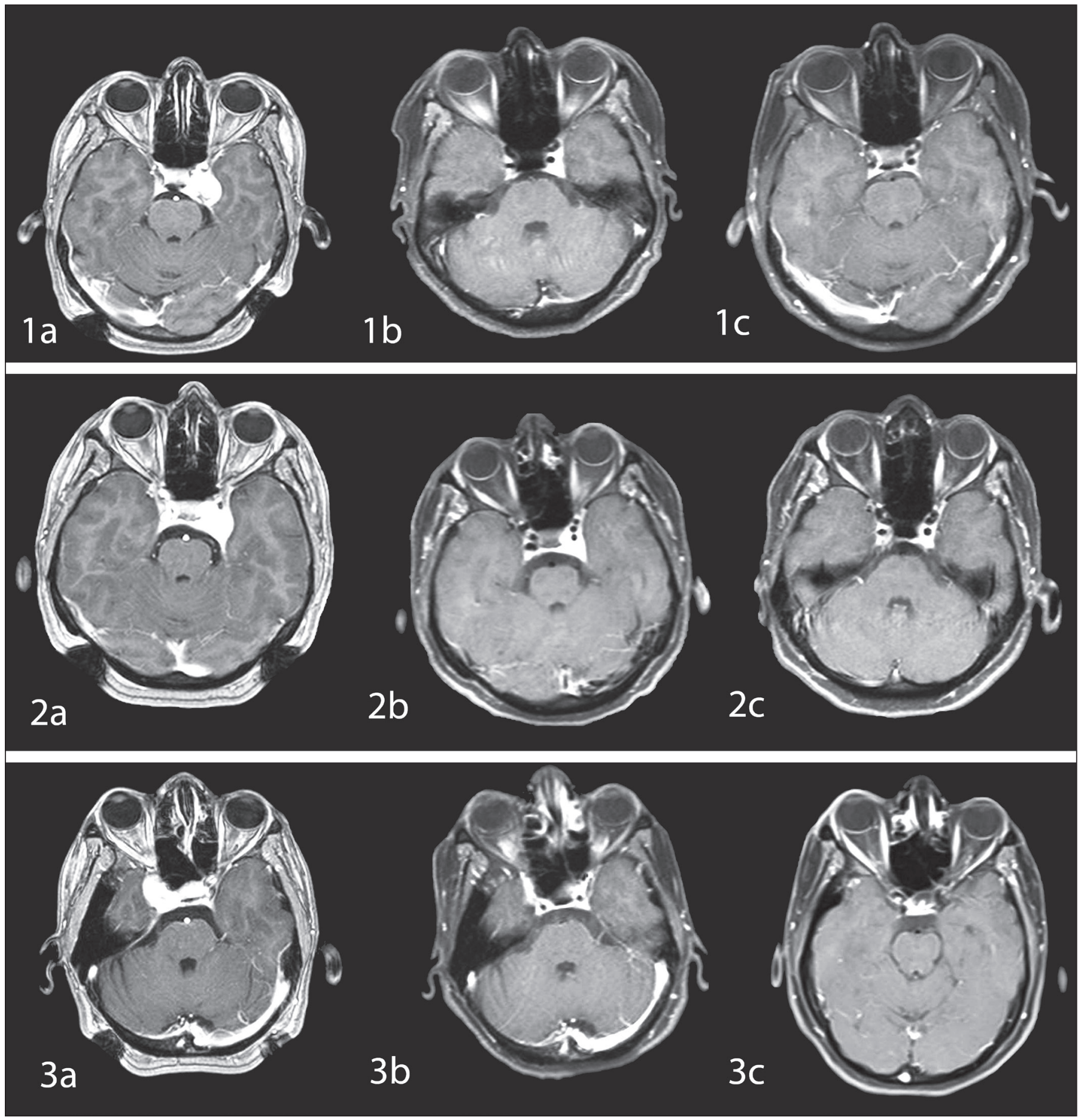

Figure 3: T1-weighted post-contrast magnetic resonance (MR) images of three different CSH patients treated with Gamma Knife radiosurgery. MR images prior to treatment (1a, 2a, 3a) show a prominent tumor in the right or left cavernous sinus. Satisfying tumor shrinkage was observed on MR images acquired 6 months (1b, 2b, 3b) and 12 months (1c, 2c, 3c) after the treatment.

\section{CONCLUSION}

The characteristic radiological features of CSH eliminate the need for open biopsy in diagnosis of $\mathrm{CSH}$. In appropriate cases, GKRS may be considered as the primary and only therapy for CSH. GKRS has favorable outcomes for the treatment of $\mathrm{CSH}$ with good tumor shrinkage, symptom recovery, and low reported side effects. 


\section{REFERENCES}

1. Chou CW, Wu HM, Huang Cl, Chung WY, Guo WY, Shih $\mathrm{YH}$, Lee LS, Pan DH: Gamma knife surgery for cavernous hemangiomas in the cavernous sinus. Neurosurgery 67:611616, 2010

2. Hori S, Hayashi N, Nomoto K, Sato H, Hayashi T, Nagai S, Nishikata M, Endo S: Cavernous sinus cavernous hemangioma largely extending in to the sella turcica and mimicking pituitary adenoma: Case report. Neurol Med Chir (Tokyo) 50:330-332, 2010

3. Ivanov P, Chernov M, Hayashi M, Nakaya K, Izawa M, Murata $\mathrm{N}$, Kubo O, Ujiie H, Muragaki Y, Nakamura R, Iseki H, Hori T, Takakura K: Low-dose Gamma Knife Radiosurgery for cavernous sinus hemangioma: Report of 3 cases and literature review. Minim Invasive Neurosurgery 51:140-146, 2008

4. Iwai Y, Yamanaka K, Nakajima H, Yasui T: Stereotactic radiosurgery for cavernous sinus cavernous hemangiomacase report. Neurol Med Chir (Tokyo) 39:288-290, 1999

5. Khan AA, Niranjan A, Kano H, Kondziolka D, Flickinger JC, Lunsford LD: Stereotactic radiosurgery for cavernous sinus or orbital hemangiomas. Neurosurgery 65:914-918, 2009

6. Kida Y, Kobayashi T, Mori Y: Radiosurgery of cavernous hemangiomas in the cavernous sinus. Surg Neurol 56:117123, 2001

7. Lee CC, Sheehan JP, Kano H, Akpinar B, Martinez-Alvarez R, Martinez-Moreno N, Guo WY, Lunsford LD, LiuKD: Gamma Knife radiosurgery for hemangioma of the cavernous sinus. J Neurosurg 126(5):1498-1505, 2017

8. Li ZH, Wu Z, Zhang JT, Zhang LW: Surgical management and outcomes of cavernous sinus hemangiomas: A singleinstitution series of 47 patients. World Neurosurg pii: S18788750(18)32562-2, 2018

9. Linskey ME, Sekhar LN: Cavernous sinus hemangiomas: A series, a review, and a hypothesis. Neurosurgery 30:101-108, 1992

10. Lombardi D, Giovanelli M, de Tribolet N: Sellar and parasellar extra-axial cavernous hemangiomas. Acta Neurochir (Wien) 130:47-54, 1994

11. Meyer FB, Lombardi D, Scheithauer B, Nichols DA: Extraaxial cavernous hemangiomas involving the dural sinuses. J Neurosurg 73:187-192, 1990
12. Mori K, Handa H, Gi H, Mori K: Cavernomas in the middle fossa. Surg Neurol 14:21-31, 1980

13. Nakamura N, Shin M, Tago M, Terahara A, Kurita H, Nakagawa K, Ohtomo K: Gamma Knife radiosurgery for cavernous hemangiomas in the cavernous sinus. Report of three cases. J Neurosurg 97 Suppl 5:477-480, 2002

14. Namba S: Extracerebral cavernous hemangioma of the middle cranial fossa. Surg Neurol 19:379-388, 1983

15. Peker S, Kilic T, Sengoz M, Pamir MN: Radiosurgical treatment of cavernous sinus cavernous hemangiomas. Acta Neurochir (Wien) 146:337-341, 2004

16. Puca A, Colosimo C, Tirpakova B, Lauriola L, DiRocco F: Cavernous hemangioma extending to extracranial, intracranial, and orbital regions. Case report. J Neurosurg 101:1057-1060, 2004

17. Seo Y, Fukuoka S, Sasaki T, Takanashi M, Hojo A, Nakamura $\mathrm{H}$ : Cavernous sinus hemangioma treated with gamma Knife radiosurgery: Usefulness of SPECT for diagnosis-case report. Neurol Med Chir (Tokyo) 40:575-580, 2000

18. Snell JW, Sheehan J, Stroila M, Steiner L: Assessment of imaging studies used with radiosurgery: A volumetric algorithm and an estimation of its error. Technical note. $J$ Neurosurg 104:157-162, 2006

19. Suzuki Y, Shibuya M, Baskaya MK, Takakura S, Yamamoto M, Saito K, Glazier SS, Sugita K: Extracerebral cavernous angiomas of the cavernous sinus in the middle fossa. Surg Neurol 45:123-132, 1996

20. Tang X, Wu H, Wang B, Zhang N, Dong Y, Ding J, Dai J, Yu T, Pan L: A new classification and clinical results of Gamma Knife radiosurgery for cavernous sinus hemangiomas: A report of 53 cases. Acta Neurochir (Wien) 157:961-969, 2015

21. Thompson TP, Lunsford LD, Flickinger JC: Radiosurgery for hemangiomas of the cavernous sinus and orbit: Technical case report. Neurosurgery 47:778-783, 2000

22. Wang X, Mei G, Liu X, Dai J, Pan L, Wang E: The role of stereotactic radiosurgery in cavernous sinus hemangiomas: $A$ systematic review and meta-analysis. J Neurooncol 107:239245, 2012

23. Yao Z, Feng X, Chen X, Zee C: Magnetic resonance imaging Characteristics with pathological correlation of cavernous malformation in cavernous sinus. J Comput Assist Tomogr 30:975-979, 2006

24. Zhou LF, Mao Y, Chen L: Diagnosis and surgical treatment of cavernous sinus hemangiomas: An experience of 20 cases. Surg Neurol 60:31-37, 2003 